Bull. Egypt. Soc. Physiol. Sci. 38(2), 175- 184

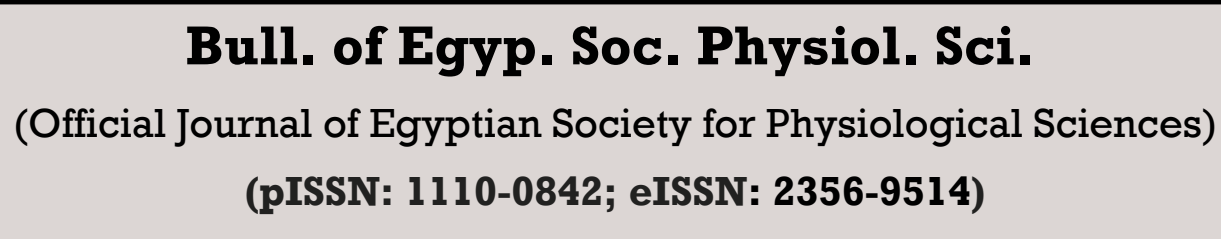

Bull. of Egyp. Soc. Physiol. Sci.

(pISSN: 1110-0842; eISSN: 2356-9514)

\title{
Serum Vitamin D levels in Rheumatoid arthritis and Relationship with disease activity
}

\author{
* Azza Elamir' ${ }^{1}$ Tarek Ibrahim², Nermeen Ahmed Fouad ${ }^{3}$, Mohamed Masoud $^{4}$ \\ ${ }^{1}$ Department of Medical Biochemistry, Faculty of Medicine, Fayoum University, Fayoum, Egypt. \\ ${ }^{2}$ Department of Internal Medicine, Faculty of Medicine, Fayoum University, Fayoum, Egypt. \\ ${ }^{3}$ Department of Rheumatology and Rehabilitation, Faculty of Medicine, Fayoum University, Fayoum, Eg \\ ${ }^{4}$ Department of public health, Faculty of Medicine, Fayoum University, Fayoum, Egypt
}

Received: 11 Nov 2017

Accepted: 12 March 2018

Available online: 1 June 2018

Keywords

- Rheumatoid arthritis

- Vitamin D

\section{Abstract}

Aim: This study was designed to measure the serum level of vitamin D in patients with rheumatoid arthritis, and to correlate it with disease activity. Method: 41 patients of Rheumatoid arthritis fulfilling the ACR/EULAR classification criteria for RA and 20 healthy controls were included in the study. Disease activity was evaluated by DAS-28 score. $25(\mathrm{OH})$ vitamin D and CRP levels were measured using ELISA Kit. Results: 9 patients had high disease activity (DAS-28 score >5.1), 25 patients had moderate disease activity (DAS 28 score 3.2-5.1, group B) and 7 patients had low disease activity (DAS-28 score $\leq 3.2$ ). Mean serum level of vitamin D of RA patients was significantly low compared to healthy controls $(\mathrm{P}<0.0001)$. There was statistically significant negative correlation between vitamin $\mathrm{D}$ and DAS-28 ( $\mathrm{r}=-0.388, \mathrm{P}=0.031)$. Conclusion: Serum level of vitamin D of RA patients was significantly low compared to healthy controls and vitamin D had statistically significant negative correlation with disease activity in RA.

Corresponding author: Dr.Azza Elamir Lecturer of Medical Biochemistry, Medical Biochemistry Department, Faculty of Medicine, Fayoum University, Fayoum, Egypt, Tel: +201013582883. Email: azzaelamer2013@gmail.com, ama27@fayoum.edu.eg 


\section{Introduction}

Vitamin D is a fat soluble vitamin which has a crucial role in metabolism of calcium and bone. It is implicated in organizing of calcium homeostasis, as it plays essential role in regulation of absorption of calcium from the gastrointestinal tract [1]. Vitamin D is formed in the skin by the effect of ultraviolet irradiation [2]. Also, Vitamin D exerts extraskeletal and immunomodulatory actions [3]. Lack of Vitamin D was displayed to be related to the pathogenesis of many autoimmune disorders, like rheumatoid arthritis, insulindependent diabetes mellitus (IDDM) and systemic lupus erythematosus [4]. Rheumatoid arthritis (RA) is an autoimmune disease that predominately influences joints. It mainly leads to destruction of joints resulting in marked disability and high mortality. Stiffness and pain usually increased after rest. Generally, the hands and wrist are implicated. The disease might also influence other portions of the body. This may lead to decreased erythrocyte count, inflammation around the lungs and the heart. High temperature and low energy might also be existing [5]. Lately, the role of deficiency of vitamin $\mathrm{D}$ in the occurrence of rheumatoid arthritis, and the correlation between vitamin D deficiency and the activity of RA is debated [6]. Addition of Vitamin D may be significant for RA patients for two causes. Vitamin $\mathrm{D}$ has a leading role in preserving adequate levels of blood calcium and retaining bone health. RA patients are specifically susceptible to osteoporosis and bone loss as a consequence of RA disease actions and corticosteroid utilize [7].

The aim of our study was to assess vitamin D status in patients with rheumatoid arthritis and to evaluate the relationship between levels of vitamin $\mathrm{D}$ and disease activity.

\section{Subjects and methods:}

The subjects of this study were selected from outpatient clinic of Rheumatology and Rehabilitation and inpatient Rheumatology and Rehabilitation department, Fayoum University Hospital, Faculty of Medicine, Fayoum University, Fayoum, Egypt. The design, objectives and methods of the study were compatible with the world medical association (WMA) declaration of Helsinki 2013. The protocol of study had been approved by the research ethical committee at Fayoum University. The protocol was discussed to all the study participants, and a written informed consent was obtained from each participant. All participants were volunteers. This study was conducted on 61 subjects were classified into 2 groups: Group (1): 20 healthy controls aged 36.1 $\pm 4.4 ; \mathbf{8}$ males $(40 \%)$ and $\mathbf{1 2}$ females (60\%). Group (2): 41 patients aged $45.9 \pm 11.0 ; 7$ males $(17.1 \%)$ and 34 females (82.9\%) diagnosed with rheumatoid arthritis with disease duration ranged between 3 and 10 years fulfilling the ACR/EULAR classification criteria for RA [8]. All patients had a full clinical and laboratory evaluation. The information about drug use and vitamin D supplementation were documented. Data about comorbidities (hypertension, diabetes, cancer, lung, liver, renal and blood diseases, hepatitis B and C) were collected and excluded from the study not to interfere with our results.

Disease activity was evaluated by calculating the 28-joint Disease Activity Score (DAS-28) [9], and was measured as (high $>5.1-3.2<$ moderate $\leq$ $5.1-2.6<$ low $\leq 3.2$ and remission $\leq 2.6$ ). 
Samples Collection Blood samples were collected from study subjects and divided into two parts. The first part was collected into vacationer EDTA tubes to assess ESR and the second part was collected in plain vacutainer tubes and was incubated at $37^{\circ} \mathrm{C}$ for ten to fifteen minutes then was centrifuged at $3000 \mathrm{rpm}$ for serum separation. ESR was measured by Westergreen method, CRP and vitamin D serum levels were assessed using Calbiotech ELISA Kit, Austin, USA [10,11] . All protocols followed the manufacturer's instructions.

Statistical analysis of data: The collected data were organized, tabulated and statistically analyzed using SPSS software statistical computer package version 18 (SPSS Inc, USA). For quantitative data, the mean, median, standard deviation (SD), and range were calculated.
Kolmogorov-Smirnov test (KS) test was performed as a test of normality; if variables were normally distributed independent t-test and One way ANOVA were used in comparing between two groups and three groups, respectively. In notnormally distributed variables, Mann-Whitney-U test was used as a test of significance to compare between two groups. Qualitative data were presented as number and percentages, chi square $(\chi 2)$ was used as a test of significance. Spearman correlation was run to identify relation between IGF-1 and study parameters. For interpretation of results of tests of significance, significance was adopted at $\mathrm{P} \leq 0.05$.

\section{Results}

Table (1): Socio-demographic characteristics of study groups.

\begin{tabular}{|l|c|c|c|}
\hline \multirow{2}{*}{ Variable } & Cases (41) & Controls (20) & \multirow{2}{*}{ P-value } \\
\cline { 2 - 3 } & \multicolumn{2}{|c|}{ Mean \pm SD } & \\
\hline Age (Years) & $45.9 \pm 11.0$ & $36.1 \pm 4.4$ & $<0.0001^{*}$ \\
\hline Variable & \multicolumn{2}{|c|}{$\mathrm{N}(\%)$} & $0.008^{*}$ \\
\hline \hline Sex: & $7(17.1)$ & $8(40.0)$ & \\
Male & $34(82.9)$ & $12(60.0)$ & \\
Female & & & \\
\hline
\end{tabular}

* Significant

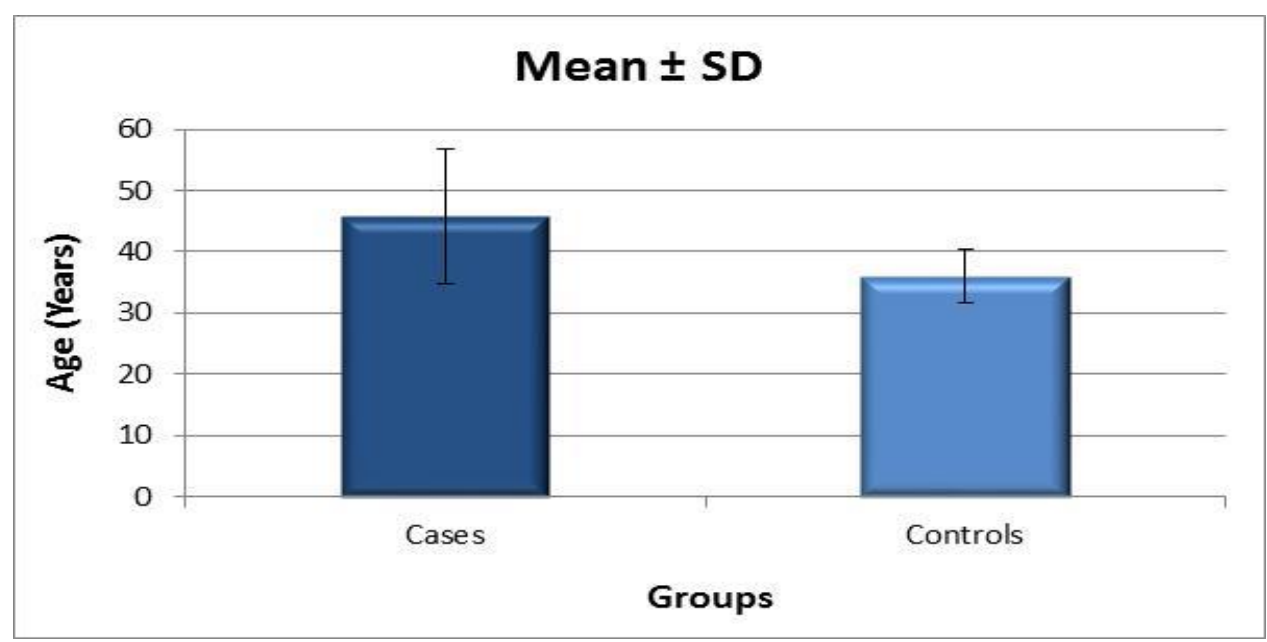

Figure (1): Age of case and control groups 
Table (2): Differences in ESR, CRP and vitamin D between case and control groups.

\begin{tabular}{|c|c|c|c|}
\hline \multirow{2}{*}{ Variable } & Cases (41) & Controls (20) & \multirow{2}{*}{ P-value } \\
\cline { 2 - 3 } & \multicolumn{2}{|c|}{ Mean \pm SD } & \\
\hline ESR $\left(\mathbf{m m} / \mathbf{1}^{\text {st }}\right.$ hour $)$ & $\mathbf{4 3 . 0 3} \pm \mathbf{7 . 3 4}$ & $\mathbf{1 2 . 0 0} \pm \mathbf{3 . 1 1}$ & $<\mathbf{0 . 0 0 0 1} *$ \\
\hline CRP $(\mathbf{m g} / \mathbf{l})$ & $\mathbf{2 2 . 8 7} \pm \mathbf{3 0 . 9 3}$ & $\mathbf{4 . 4 3} \pm \mathbf{2 . 8 8}$ & $\mathbf{0 . 0 0 3}{ }^{*}$ \\
\hline \hline Vitamin D $(\mathrm{ng} / \mathrm{ml})$ & $\mathbf{2 0 . 9 9} \pm \mathbf{6 . 1 3}$ & $\mathbf{7 3 . 8 9} \pm \mathbf{1 5 . 2 4}$ & $<\mathbf{0 . 0 0 0 1}^{*}$ \\
\hline
\end{tabular}

*significant

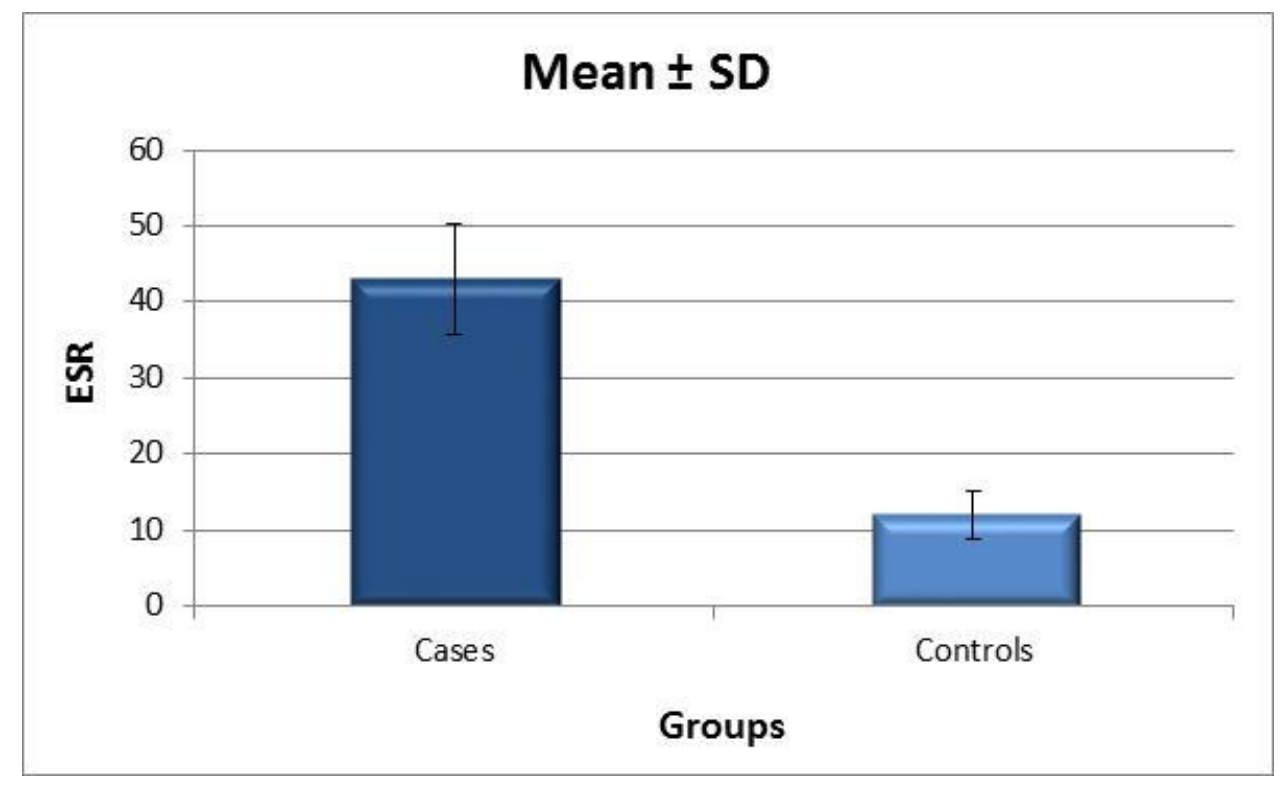

Figure (2): ESR in case and control groups.

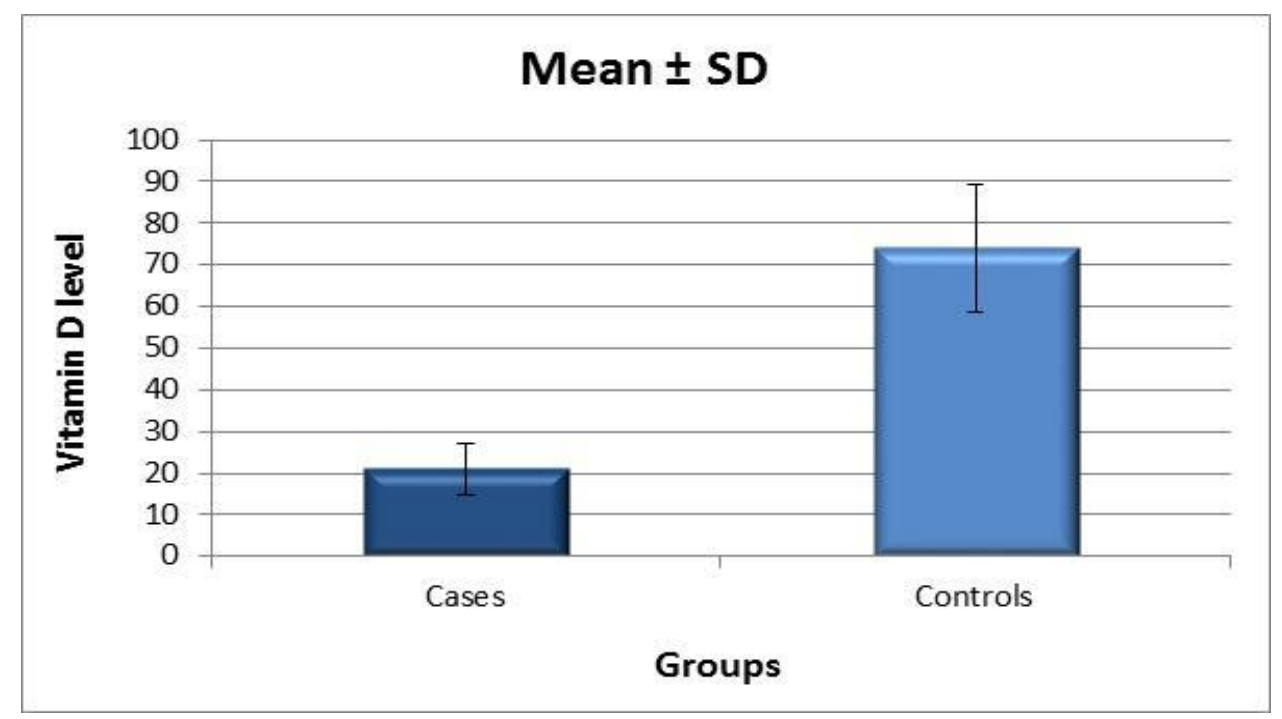

Figure (3): Vitamin D level in case and control groups.

There were statistically significant differences in ESR, CRP and serum vitamin D between study groups with $\mathrm{P}$-value $<0.0001,0.003$ and < 0.0001 respectively. 
Table (3): Differences in vitamin D regarding Disease Activity Score (DAS-28)

\begin{tabular}{|c|c|c|}
\hline DAS-28 & Mean \pm SD & P-value \\
\hline Low $(\mathrm{N}=9)$ & $21.38 \pm 8.31$ & \multirow{2}{*}{0.606} \\
\cline { 1 - 2 } Moderate $(\mathrm{N}=25)$ & $19.22 \pm 6.06$ & \\
\hline Severe $(\mathrm{N}=7)$ & $16.64 \pm 1.25$ & \\
\hline
\end{tabular}

There was decrease in serum level of vitamin D with increasing Disease Activity Score (DAS-28)

but this decrease in not statistically significant between 3 categories.

Table (4): Correlations between vitamin D level and different parameters among cases

\begin{tabular}{|c|c|c|}
\hline \multirow{2}{*}{} & \multicolumn{2}{|c|}{ Vitamin D level } \\
\cline { 2 - 3 } & $\mathbf{r}$ & P-value \\
\hline Age & $\mathbf{- 0 . 5 0 6}$ & $<\mathbf{0 . 0 0 0 1 *}$ \\
\hline Disease duration & $\mathbf{0 . 0 4 8}$ & $\mathbf{0 . 7 9 6}$ \\
\hline DAS-28 & $\mathbf{- 0 . 3 8 8}$ & $\mathbf{0 . 0 3 1 *}$ \\
\hline ESR & $\mathbf{- 0 . 4 8 6}$ & $\mathbf{0 . 0 0 6 *}$ \\
\hline CRP & $\mathbf{- 0 . 3 5 8}$ & $\mathbf{0 . 0 4 8 *}$ \\
\hline
\end{tabular}

\section{* Significant}

There were statistically significant negative correlations between vitamin $\mathrm{D}$ and age $(\mathrm{r}=$ -

0.506), DAS-28 $(r=\mathbf{- 0 . 3 8 8}), \operatorname{ESR}(r=\mathbf{- 0 . 4 8 6})$ and $\mathrm{CRP}(\mathrm{r}=\mathbf{- \mathbf { 0 . 3 5 8 }})$ among cases.

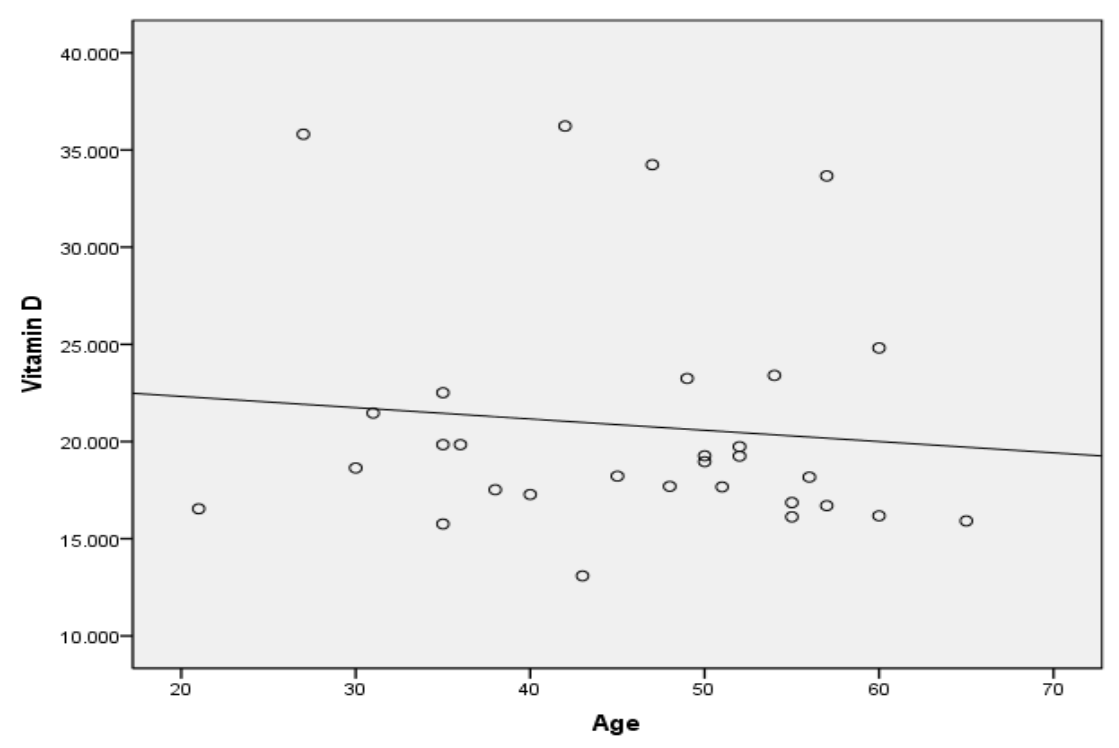

Figure (4): Correlation between vitamin D level and age among cases. 


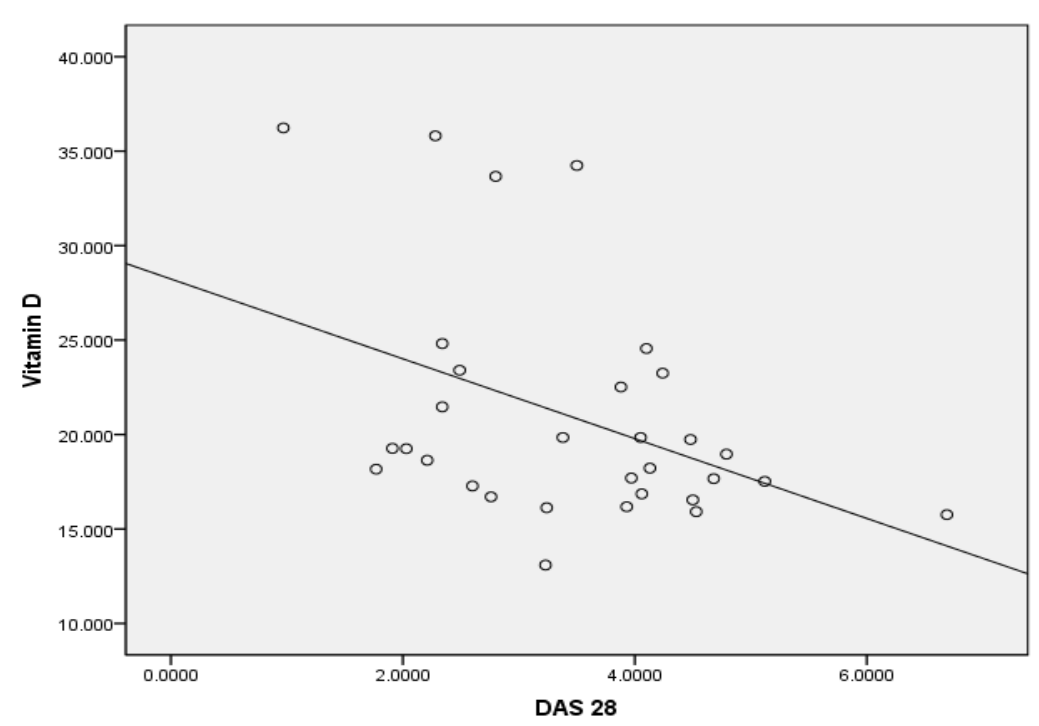

Figure (5): Correlation between vitamin D level and DAS-28 among cases.

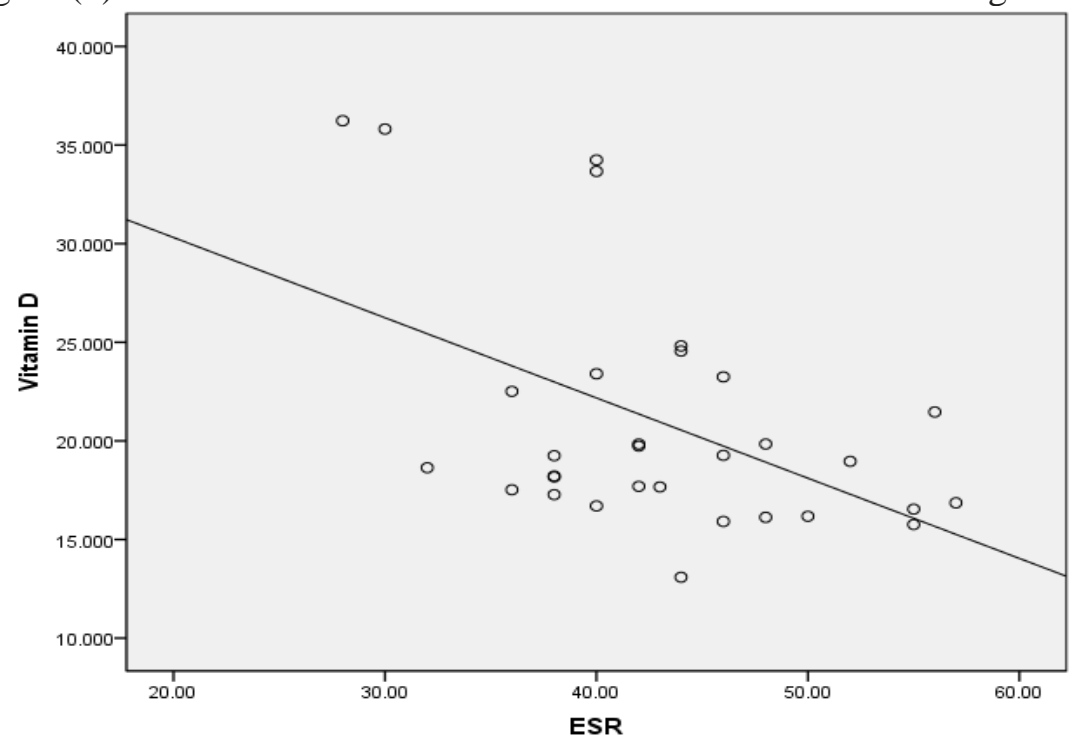

Figure (6): Correlation between vitamin D level and ESR among cases.

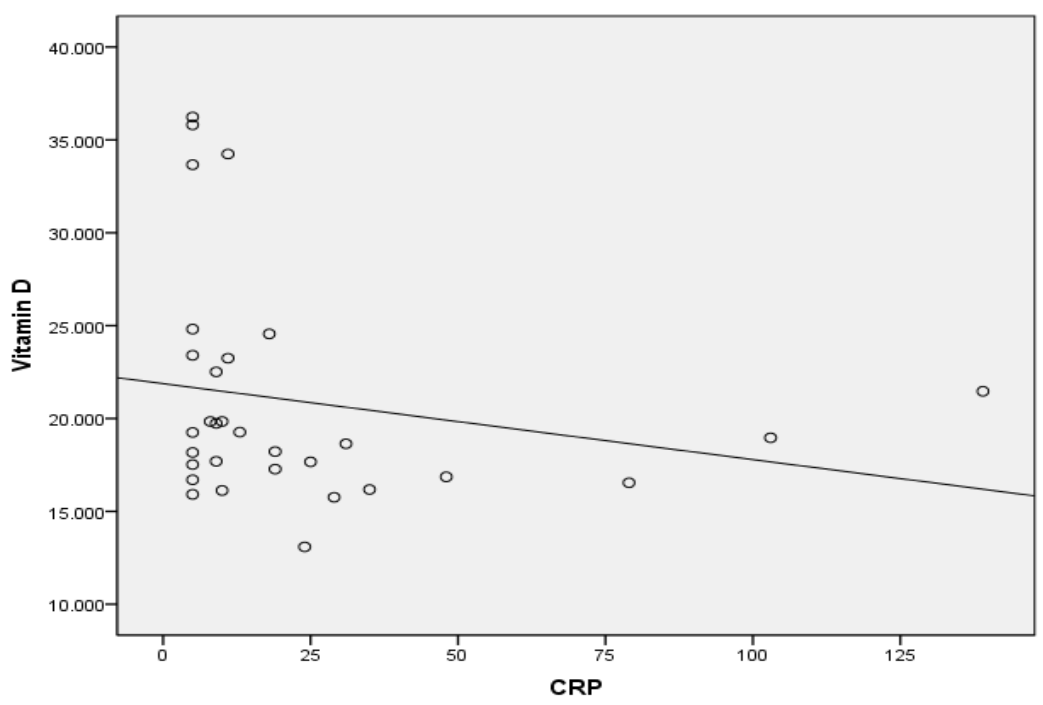

Figure (7): Correlation between vitamin D level and CRP among cases. 


\section{Discussion:}

Vitamin $\mathrm{D}$ is recognized to stimulate Immune response [12]. So, deficiency of vitamin D might disturb immunological response and stimulate the occurrence of autoimmune diseases, including rheumatoid arthritis. Vitamin D possesses immunoregulatory features, performing on the immune system in both paracrine and endocrine a pattern [3]. It seems to modulate the immunological tolerance by a diversity of mechanisms, as diminishing antigen presentation, blocking the proinflammatory $\mathrm{T}$ helper type 1 profile and stimulating regulatory $\mathrm{T}$ cells [13].

Vitamin D represses antibody synthesis and proliferation and delays differentiation of B-cell precursors into plasma cells. These facts boost a role for deficiency of vitamin $\mathrm{D}$ in the occurrence and advancement of autoimmune inflammatory disorders specially RA [14].

Deficiency of Vitamin D was intensely accompanied by disabling manifestations amongst those with rheumatoid arthritis, this according to a 2012 Greek study stated in Therapeutic advancement in Endocrinology and Metabolism. This is might be resulting from the finding that RA can influence capability of the body to absorb vitamin D from meals, and when levels of vitamin $\mathrm{D}$ are decreased, RA pain and manifestations might worsen[15].

There is potent proof concerning RA progression or severity that seems to be related to vitamin $\mathrm{D}$ deficiency. RA Patients who have vitamin D deficiency are less potentially to attain remission. This does not imply that vitamin $\mathrm{D}$ is essential to attain remission, but, because active RA could affect mobility [16].

Supplementation with vitamin D and enhanced exposure to sunlight - could assist to minimize inflammation, strengthen bone cartilage, reduce pain and decrease disability risk. Supplementation with vitamin D could also assist to relieve other symptoms of arthritic conditions [17].

A study of the Albert Einstein University of Medicine of Yeshiva University in New York City, reported that individuals who take corticosteroid therapy are twice as probably to have deficiency of vitamin $\mathrm{D}$, compared to those who don't take it. Corticosteroid therapy, like prednisone, that patients with RA take to minimize inflammation, could decrease absorption of calcium and disrupt metabolism of vitamin D. Other medications for RA, like Hydroxychloroquine and immunosuppressants are also related to impaired vitamin $\mathrm{D}$ absorption. So patients with RA taking these medications should regularly assess their level of vitamin D [18].

In the present study, we found serum level of vitamin $\mathrm{D}$ in patients of RA was significantly low compared to healthy controls.

These results were in disagreement with the results obtained from Rossini et al which displayed that vitamin D deficiency is equally common in patients of RA and healthy controls[19].

According to our study, we found Vitamin D levels were negatively correlated with disease activity in RA patients.

Many studies have shown the relation between level of vitamin D and disease activity in RA. Rossini et al and Haque and Bartlett reported an 
inverse correlation between vitamin D levels and disease activity in RA [20,19]. Kerr et al and Welsh et al proved that deficiency of vitamin $\mathrm{D}$ is related to disease activity in $\mathrm{RA}[21,22]$.

Others did not state a relation between deficiency of vitamin D and disease activity in RA [23,24,25].

Kerr et al also showed that deficiency of vitamin $\mathrm{D}$, was independently accompanied by high number of painful joints and high levels of CRP[21].

RA Patients are susceptible to osteoporosis [26] and complain of pain when the disease is in flare. Vitamin D is prescribed for RA patients for the prevention and treatment of osteoporosis and for its potential impacts on disease activity [27].

This study had limitations as the small number of RA male patients that did not permit us to get results of value to evaluate the effect of gender on Vitamin D levels. Also, the number of controls was not gender matched with the patients. Correlation between radiological findings and vitamin D levels in the RA patients was not done; however, it would have added considerable information and would be taken into consideration in further studies.

\section{CONCLUSION}

Deficiency of Vitamin D is common in RA patients, and could be related to disease activity in RA. These results possess therapeutic impacts because deficiency of vitamin D was related to musculoskeletal pain. Supplementation with Vitamin D might be required to prevent osteoporosis and to relieve pain in patients with RA.

\section{CONCLUSION}

Plasma circRNA (0054633) expression could be considered as a predictive biomarker for prediabetes and hence it is a useful convenient tool for early detection of T2DM. We recommend further researches to evaluate circRNA as new target to decrease the progression of pre-diabetes into diabetes and to delay the incidence of diabetes mellitus complication.

\section{REFERENCES}

1. Holick M.: Vitamin D: evolutionary, physiological and health perspectives. Curr Drug Targets 12: 4-18, 2011

2. Mason R., Sequeira V., Gordon-Thomson C.: Vitamin D: the light side of sunshine. Eur $J$ Clin Nutr 65: 986-993, 2011

3. Hewison M.: Vitamin D and immune function: autocrine, paracrine or endocrine? Scand J Clin Lab Invest Suppl 243: 92-102, 2012

\section{Jankosky C., Deussing E., Gibson R.,}

Haverkos H. : Viruses and vitamin D in the etiology of type 1 diabetes mellitus and multiple sclerosis. Virus Res 163: 424-430, 2012

5. Mason JC. Rheumatic diseases and the cardiovascular system. In: Mann DL, Zipes DP, Libby P, Bonow RO, Braunwald E, eds. Braunwald's Heart Disease: A Textbook of Cardiovascular Medicine. 10th ed. Philadelphia, PA: Elsevier Saunders; chap 84, 2015

6. Song G., Bae S., Lee Y.: Association between vitamin $\mathrm{D}$ intake and the risk of rheumatoid arthritis: a meta-analysis. Clin Rheumatol; 31(12): 1733-9, 2012.

7. Salesi M, Farajzadegan Z: Efficacy of vitamin $\mathrm{D}$ in patients with active rheumatoid arthritis 
receiving methotrexate therapy. Rheumatol Int; 32:2129-33, 2012

\section{Aletaha D, Neogi T, Silman AJ, Funovits J,}

Felson DT: Rheumatoid arthritis classification criteria: an American College of Rheumatology/European League Against Rheumatism collaborative initiative. Arthritis Rheum. ; 62(9):2569, 2010.

\section{Prevoo ML, van 't Hof MA, Kuper HH, van} Leeuwen MA, Van de Putte LB, Van Riel PL: Modified disease activity scores that include twenty-eight-joint counts. Development and validation in a prospective longitudinal study of patients with rheumatoid arthritis. Arthritis Rheum 38:44-48, 1995.

10. Holick, MF. Vitamin D Status: Measurement, Interpretation and Clinical Application: Ann Epidemoil., 19(2):73 - 78, 2009.

11. Macy, E.M., Hayes, T.E., and Tracy, R.P.: Variability in the measurement of Creactive protein in healthy subjects: implications for reference interval and epidemiological applications. Clin Chem, 43; 1:52-58, 1997.

12. Weiss, S.: Bacterial components plus vitamin D: the ultimate solution to the asthma (autoimmune disease) epidemic? J Allergy Clin Immunol 127: 1128-1130, 2011.

13. Bartels, L., Hvas, C., Agnholt, J., Dahlerup, J. and Agger, R.: Human dendritic cell antigen presentation and chemotaxis are inhibited by intrinsic 25-hydroxy vitamin $\mathrm{D}$ activation. Int Immunopharmacol 10: 922-928, 2010.

14. Chen, S., Sims, G., Chen, X., Gu, Y., Chen, S. and Lipsky, P.: Modulatory effects of 1,25dihydroxyvitamin D3 on human B cell differentiation. J Immunol 179: 1634-1647, 2007.
15. Lin, J., Liu, J., Davies, M. and Chen, W. : "Serum Vitamin D level and rheumatoid arthritis disease activity: Review and meta-analysis," PLoS ONE, vol. 11 (1), 2016

16. Cherniack EP. A Ray of Hope for Tender Joints: Vitamin D and Rheumatoid Arthritis. $J$ Rheumatol ;38;5-7, 2011

17. Baykal, T., Senel, K., Alp, F., Erdal, A. and Ugur, M.: "Is there an association between serum 25-hydroxyvitamin D concentrations and disease activity in rheumatoid arthritis?" Bratislava Medical Journal, vol. 113, (10): 610-611, 2012.

18. Jirapongsananuruk O., Melamed I., Leung D.: Additive immunosuppressive effects of 1,25dihydroxyvitamin D3 and corticosteroids on TH1, but not TH2, responses. $J$ Allergy Clin Immunol106: 981-985, 2000.

19. Haque, U. and Bartlett, S.: Relationships among vitamin $\mathrm{D}$, disease activity, pain and disability in rheumatoid arthritis. Clin Exp Rheumatol 28: 745-747, 2010.

20. Rossini, M., Maddali Bongi, S., La Montagna, G., Minisola, G., Malavolta, N., Bernini, L. et al.: Vitamin D deficiency in rheumatoid arthritis: prevalence, determinants and associations with disease activity and disability. Arthritis Res Ther 12: R216, 2010.

21. Kerr, G., Sabahi, I., Richards, J., Caplan, L., Cannon, G., Reimold, A. et al.: Prevalence of vitamin D insufficiency/deficiency in rheumatoid arthritis and associations with disease severity and activity. J Rheumatol 38: 53-59, 2011.

22. Welsh, P., Peters, M., McInnes, I., Lems, W., Lips, P., McKellar, G. et al.: Vitamin D deficiency is common in patients with RA and linked to disease activity, but circulating levels are unaffected by $\mathrm{TNF} \alpha$ blockade: results from a 
prospective cohort study. Ann Rheum Dis 70: 1165-1167, 2011.

23. Craig, S., Yu, F., Curtis, J., Alarcn, G., Conn, D., Jonas, B. et al.: Vitamin D status and its associations with disease activity and severity in African Americans with recent-onset rheumatoid arthritis. J Rheumatol 37: 275-281, 2010.

24. Braun-Moscovici, Y., Toledano, K., Markovits, D., Rozin, A., Nahir, A. and BalbirGurman, A.: Vitamin D level: is it related to disease activity in inflammatory joint disease? Rheumatol Int 31: 493-499, 2011.

25. Baker, J., Baker, D., Toedter, G., Shults, J., Von Feldt, J. and Leonard, M.: Associations between vitamin $\mathrm{D}$, disease activity, and clinical response to therapy in rheumatoid arthritis. Clin Exp Rheumatol 30: 658-664, 2012.

26. Deal, C.: Bone loss in rheumatoid arthritis: systemic, periarticular, and focal. Curr Rheumatol Rep 14: 231-237, 2012.

27. Varenna, M., Manara, M., Cantatore, F., Del Puente, A., Di Munno, O., Malavolta, N. et al.: Determinants and effects of vitamin D supplementation on serum 25-hydroxy-vitamin D levels in patients with rheumatoid arthritis. Clin Exp Rheumatol 30: 714-719, 2012. 